\title{
The Liverpool Bay Coastal Observatory
}

\author{
JOHN HOWARTH, ROGER PROCTOR, CHRIS BALFOUR, PHIL KNIGHT, \\ MATTHEW PALMER, ROSE PLAYER
}

Proudman Oceanographic Laboratory, 6 Brownlow Street, Liverpool L3 5DA UK

email: $\underline{\text { mjh@pol.ac.uk }}$

Keywords: Irish Sea, Coastal Observatory

\begin{abstract}
Introduction

A pre-operational Coastal Observatory has been operating since August 2002 in Liverpool Bay, Irish Sea. Its rationale is to develop the science underpinning the ecosystem based approach to marine management, including distinguishing between natural and man-made variability, with particular emphasis on eutrophication and predicting possible impacts of climate change. Liverpool Bay has strong tidal mixing, receives fresh water principally from the Dee, Mersey and Ribble estuaries, each with different catchment influences, and has enhanced levels of nutrients. Horizontal and vertical density gradients are variable both in space and time. The water column stratifies intermittently. The challenge is to understand and model accurately this variable region which is turbulent, turbid, receives enhanced nutrients and is productive.
\end{abstract}

The Observatory, with emphasis on physical and chemical / biological variables, has three components, for each of which the goal is at least some (near) real time operation - measurements; coupled 3-D hydrodynamic, wave and ecological numerical models; a data management and web-based data delivery system, see http://coastobs.pol.ac.uk (Howarth et al., 2006). In the next few years the Observatory will expand in spatial coverage and in capability, for instance through the deployment of gliders, forming a focus for Irish Sea studies.

\section{$\underline{\text { Measurements }}$}

The integrated measurements are designed as a whole to test numerical models, provide a framework and basis for process studies and have as a major objective obtaining multi-year records, covering tidal, event (storm / calm / bloom), seasonal and interannual time scales. The four main strands, each on different complementary space or time scales are, Figure 1:-

a) fixed point time series (both in situ and shore-based); very good temporal and very poor spatial resolution. b) regular (nine times per year) spatial water column surveys on a $9 \mathrm{~km}$ grid; good vertical resolution for some variables, limited spatial coverage and resolution, and limited temporal resolution.

c) HF radar for surface currents and waves; very good temporal resolution, limited spatial resolution (4 km grid) and range ( $75 \mathrm{~km}$ ) (Howarth et al., 2007).

d) an instrumented ferry on the Birkenhead to Dublin route; along track $100 \mathrm{~m}$ resolution, crossing there and back most days (Balfour et al., 2007).

These measurements are supplemented by weekly composite (because of cloud cover) satellite images of sea surface temperature, suspended sediment and chlorophyll; excellent horizontal resolution for surface properties, poor temporal coverage.

The fixed point time series measurements include shore based tide gauges, a meteorological station on Hilbre Island at the mouth of the Dee, two in situ sites, one by the Mersey Bar, measuring waves and the vertical structure of current, temperature and salinity, along with a surface CEFAS SmartBuoy whose measurements include nutrients (Mills, et al. 2005). Offshore surface data are transmitted in near real time to the laboratory via the Orbcomm low earth orbit satellite e-mail system. Some subsurface data are also telemetered to the surface via an acoustic modem for onward transmission. In addition river flows are gauged by the Environment Agency. 


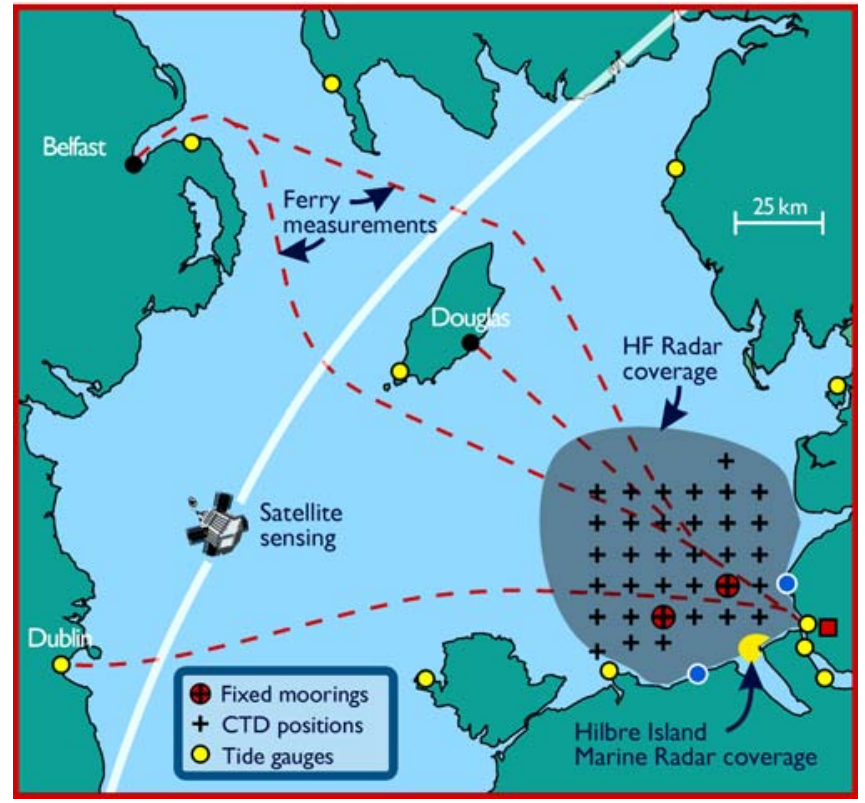

Figure 1. Scheme of measurements

The cruises, to service the two in situ sites and conduct the water column surveys, on RV Prince Madog, a coastal research vessel, have attracted significant extra interest including making increased measurements of nutrients with now an on board analyser on some cruises, grab sampling, swathe-bathymetry, microbial degradation measurements, and twice yearly benthic biological sampling at the two in situ sites. The suite of measurements is being enhanced with on board $\mathrm{pCO}_{2}$ measurements, now routine showing at times Liverpool Bay is a net source of $\mathrm{CO}_{2}$ and at other times a net sink. Dissolved oxygen is being measured on the ferry, as well as temperature, conductivity, fluorescence and turbidity, and at the surface and bed at the Mersey Bar site (seen as another avenue for estimating productivity).

\section{Modelling}

A suite of coupled 3-D hydrodynamic, wave and ecological models forced by forecast meteorology is being developed. The model domains are nested from a $12 \mathrm{~km}$ grid for the ocean / shelf domain, to $7 \mathrm{~km}$ for the north-west European continental shelf, to $1.8 \mathrm{~km}$ for the Irish Sea, finally to $180 \mathrm{~m}$ for Liverpool Bay. Seeking to make realistic real time forecasts for comparison with measurements is difficult since the forecast will only be as good as the forcing data, for instance meteorological inputs from numerical models should be on a spatial scale comparable with the oceanographic models'. Also river flow data need to be in real time (climatological mean data are not good enough, especially for local models). To obtain maximum benefit from the measurements, data are being assimilated into the models - a start has been made with satellite sea surface temperature, HF radar and ferry data.

The measurements and model results are displayed on the web site (http://coastobs.pol.ac.uk), from where they can also be downloaded. Access to the data is free - the largest groups of users are the general public, researchers and education. We are seeking to establish better links particularly with local authorities and central government but also with commercial users to improve applicability and usage. The data are banked with the British Oceanographic Data Centre.

\section{$\underline{\text { Results }}$}

The Irish Sea is semi-enclosed so that despite at times strong, over $30 \mathrm{~m} \mathrm{~s}^{-1}$, westerly winds blowing across the British Isles, waves in Liverpool Bay are locally generated with maximum significant wave heights of 5.4 $\mathrm{m}$ and peak periods of $12 \mathrm{~s}$. However for $68 \%$ of the measurements the significant wave height is less than 1 $\mathrm{m}, 92 \%$ less than $2 \mathrm{~m}$ and $98 \%$ less than $3 \mathrm{~m}$. The notable features of the currents in Liverpool Bay, which is relatively shallow (less than $50 \mathrm{~m}$ ), are the tides (over $1 \mathrm{~m} \mathrm{~s}^{-1}$ at spring tides), persistent mean currents and the lack of strong residual, wind driven, currents (less than $0.3 \mathrm{~m} \mathrm{~s}^{-1}$ ). The mean current pattern driven by the horizontal density gradient (Verspecht et al., this vol.) is of south or southeastward, shoreward, flow near the bed and northward flow near the surface of a few $\mathrm{cm} \mathrm{s}^{-1}$. 

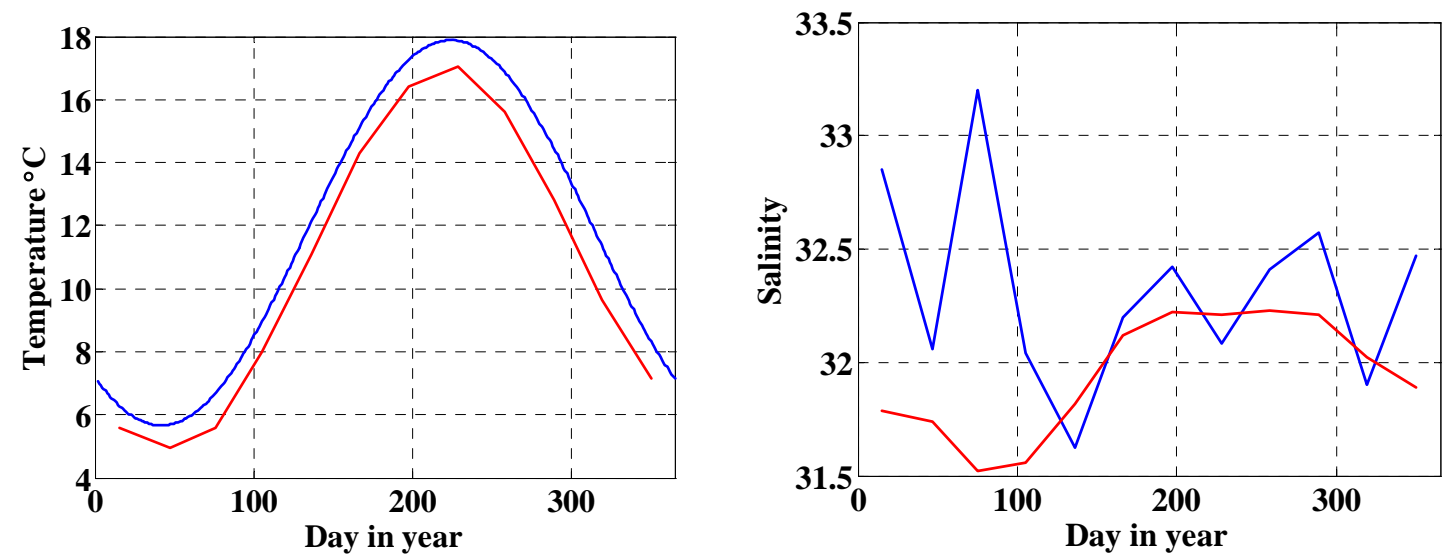

Figure 2. Surface temperature and salinity measurements from the Mersey Bar (blue) compared with monthly means from 1935 - 1969 (red).

In the five year period there have been over 50 cruises. The CTD stations show that temperature is dominated by the seasonal cycle, accounting for more than $95 \%$ of the variance at each site, Figure 2a. In contrast, for salinity the seasonal cycle accounts for less than $40 \%$ of the variance, variable spatially and at most sites less than $10 \%$, Figure 3 . For instance Figure $2 \mathrm{~b}$ shows the annual signal from month by month averages in blue. There are interannual variations in salinity but a longer data set is needed to elucidate the driving forces, for instance river discharge or changes in circulation, and responses. Comparison with earlier measurements at the Mersey Bar show that the water has warmed by $1.1^{\circ} \mathrm{C}$ relative to $1935-61$ (Hughes, 1966), in line with warming air temperatures but that salinities probably have not changed, Figure 2.

Liverpool Bay is an interesting region, on the edge of well mixed water to the west, near Anglesey; the latter a consequence of tidal mixing being sufficiently vigorous to mix heat and salinity inputs uniformly through the water column. Hence much of Liverpool Bay, apart from the shallowest areas, stratifies weakly in early summer by a few degrees centigrade in a complex interaction involving competition between buoyancy inputs (surface heat flux and freshwater from rivers and rainfall) and mixing by tides, (weaker than further west), winds and waves. The intermittent nature of the stratification is discussed by Howlett et al., this volume. Being able to predict the variable water column structure and also the penetration of light with depth in these turbid waters is an essential prerequisite for biological modelling.

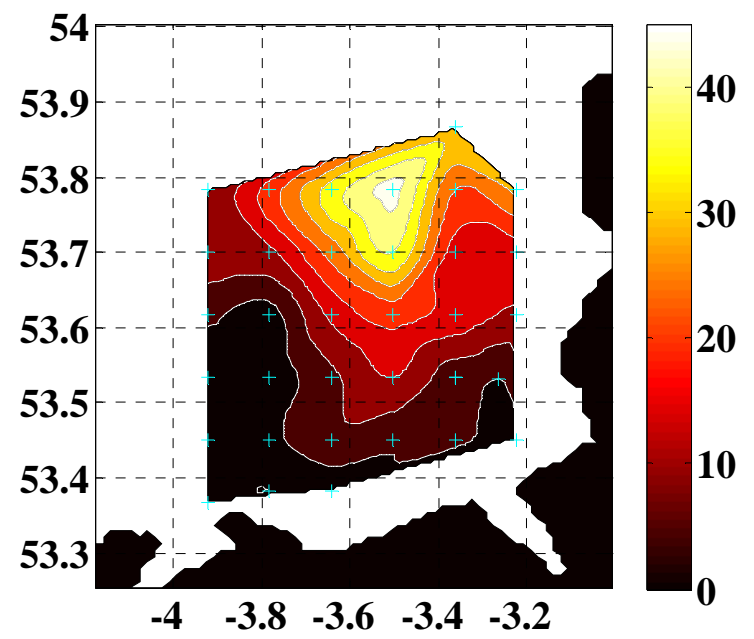

Figure 3: Per cent of the variance in the seasonal cycle for near bed salinity. The contours are at intervals of $5 \%$. 
For example, suspended sediment in the water column tends to settle out as tidal mixing decreases towards neap tides, allowing light to penetrate deeper and thus triggering a bloom if sufficient nutrients are available which happens intermittently throughout the summer from river discharge. The time taken for the bloom to reach maximum means counter-intuitively this can occur when the water column is most turbid, at the following spring tide.

\section{Conclusions}

The Liverpool Bay Coastal Observatory is unique, bringing together measurements on a wide range of space and time scales with a comprehensive modelling suite and a data management and web-based data delivery system. It has been in operation over 5 years. However such observing systems are resource hungry, in terms of equipment, cash and especially in people. Its design naturally involved compromises, for instance should the detailed geographic coverage be wider, including more of the Irish Sea, and / or should it extend closer to the shore, where biologically activity is greater? How many cruises should there be per year - nine visits, if achieved, will over-sample for a well defined seasonal cycle, such as temperature, but not for a variable with a more unpredictable or shorter time scale, such as salinity or phytoplankton? It is a perpetual struggle to ensure high data returns and data quality, with some variables easier to measure, for instance temperature, and others more difficult, sensors subject to fouling by sediment or to biofouling in the case of optics. There are also a range of outputs - scientific, management related, public awareness - which makes it more difficult to assess the Observatory's performance and effectiveness.

After five years the main scientific challenges remain both in understanding processes and in translating this understanding into predictive models whose accuracy has been quantified and which make best use of the measurements. The challenges relate to the physical environment (salinity, circulation in Liverpool Bay, the flow through the Irish Sea, flushing events); the role of sediments in the optical characteristics of the water column; the ecosystem and eutrophication. Only once these building blocks are in place will it be possible to predict possible impacts of climate change.

In the next few years the Observatory will expand collaboratively in spatial coverage to encompass the whole Irish Sea, both in acknowledgement of imminent UK and EU legislation but also because the Irish Sea embraces a wide variety of water column structure and of ecohydrodynamic regimes and is a better defined oceanographic entity. It is an excellent test bed for any continental shelf sea. The Observatory will also expand in capability, for instance through the deployment of a glider, by operating a second instrumented ferry on the Birkenhead to Belfast route and by maintaining a third in situ site.

\section{References}

Balfour, C.A., Howarth, M.J., Smithson, M.J., Jones, D.S., Pugh, J. (2007) The use of ships of opportunity for Irish Sea based oceanographic measurements. 6 pp. in, Oceans '07 IEEE Aberdeen, conference proceedings. Marine challenges: coastline to deep sea. Aberdeen, Scotland: IEEE Catalog No. 07EX1527C.

Howarth, M.J., Proctor, R., Knight, P.J., Smithson, M.J., Mills, D.K. (2006) The POL Liverpool Bay Coastal Observatory. Proceedings of the World Maritime Technology Conference, 6-10 March 2006, London, pp5.

Howarth, M.J., Player, R.J. Wolf, J., Siddons, L.A. (2007) HF radar measurements in Liverpool Bay, Irish Sea. 6 pp. in, Oceans '07 IEEE Aberdeen, conference proceedings. Marine challenges: coastline to deep sea. Aberdeen, Scotland: IEEE Catalog No. 07EX1527C.

Hughes, P. (1966), The temperature and salinity of surface waters of the Irish Sea for the period $1947-61$. Geophysical Journal of the Royal Astronomical Society, 10, 421 - 435.

Mills, D.K., Greenwood, N., Kröger, S., Devlin, M., Sivyer, D.B., Pearce, D., Cutchey, S., Malcolm, S.J. (2005), New approaches to improve the detection of eutrophication in UK coastal waters, Environmental research, engineering and management, 2(32), $36-42$. 